\title{
Teología de la vocación religiosa *
}

\section{LA VOCACION RELIGIOSA COMO CARISMA}

1. El Cuerpo Místico y los carismas.

El carácter esencialmente dinámico del Cuerpo Místico y los carismas: ministeriales y no institucionales.

En la doctrina de San Pablo y en la teología moderna se llama carisma a toda clase de auxilios o dones concedidos por Dios a los fieles sin distinción. Incluye, pues, tanto a la gracia y dones ordenados en primer lugar a la santificación del individuo (gratia gratum faciens) como a los dones otorgados directamente para el bien de la comunidad (gratia gratis data). San Pablo no hace distinción entre esas dos clases de dones, y los considera como elementos esenciales del Cuerpo de Cristo, de su dinamismo social y sobrenatural, porque en su virtud crece y se desarrolla sin cesar.

El dinamismo esencial del Cuerpo de Cristo aparece claramente en al sentido semítico de la metáfora paulina. El cuerpo (sôma) es un instrumento del todo necesario para el hombre, íntimamente unido e identificado con él. La dicotomía entre el cuerpo y el alma, como dos sustancias que integran al hombre y que pueden separarse, es ya más bien un concepto helénico, que no penetró en el mundo judío hasta el s1. glo ir. Por eso, la comunidad eclesial tiene para el Apóstol un desarrollo análogo al del hombre perfecto (sôma). Ahora bien; según la mentalidad hebrea, la vida íntima del hombre, que se manifiesta por medio del cuerpo, no le viene de sí mismo, sino del mismo Dios, de quien recibe el espíritu de la vida (ruah) y al cual volverá al fin ${ }^{1}$. Por eso, la Iglesia,

\footnotetext{
* Publicamos aquí íntegras las dos conferencias del autor en la II Semana Nacional de Vocaciones (Pamplona, 19-24 agosto 1968).

1 Eccle. 12, 7; Sab. 16, 14; Salmo 78, 39; Salmo 104, 29-30.
} 
Cuerpo de Cristo, recibe de su Cabeza la dinamis, virtud o Espiritu que la vivifica. San Pablo lo llama Espíritu del Señor o Espíritu de Cristo ${ }^{2}$. A él le atribuye la regeneración o renovación del hombre por el bautis$\mathrm{mo}^{3}$; él gime por nosotros con gemidos inenarrables, porque no sabemos cómo orar ${ }^{4}$; y, finalmente, él es el que distribuye según su voluntad todos los carismas, dones y frutos a los miembros del Cuerpo de Cristo ${ }^{5}$.

La caridad o agapé, sin la cual todos los demás dones no servirían de nada para la salvación ${ }^{6}$, es derramada por el Espíritu Santo que nos ha sido dado 7 , y es la que hace que todo el Cuerpo de Cristo y cada uno de sus miembros crezcan y se perfeccionen hasta llegar a la plenitud del hombre perfecto: "abrazados a la verdad, en todo crezcamos en caridad, llegándonos a aquel que es nuestra cabeza, Cristo, de quien todo el cuerpo, trabado y unido por todos los ligamentos que lo unen y nutren para la operación propia de cada miembro, crece y se perfecciona en la caridad" 8 .

Esa caridad o agapé es a la vez el amor de Dios al hombre y a la Iglesia, y el don que Dios les otorga para que le amen, y vivan y se perfeccionen unidos a él ${ }^{9}$.

Los carismas son, pues, un elemento esencial del Cuerpo Místico de Cristo, que debe crecer y perfeccionarse sin cesar en virtud del dinamismo que le infunde de continuo su Cabeza, Cristo, mediante el Espíritu.

El carisma deL ministerio ${ }^{10}$.- Entre los carismas o gracias que el Espíritu otorga a los miembros del Cuerpo de Cristo se halla el carisma del ministerio o diaconía, instituído por el mismo Cristo para el servicio de la comunidad, designado por San Pablo con términos que implican

Rom. 8, 9; II Cor. 3, 17; Gal. 4, 6, etc.

Tit. 3, 5; I Cor. 12, 13.

4 Rom. 8, 26-27.

5 I Cor. 12, 4 ss.; Gal. 5, 22.

6 I Cor. 13.

7 Rom. 5, 5.

8 Efes. 4, 15-16; Colos. 2, 19.

9. Cfr. C. SpICQ, O. P., Agapé dans le Nouveau Testament. Analise de Textes, I, Paris 1958; II, 1959; K. PrüMM, S. J., "Das dynamische als GrundAspekt der Heilsordnung in der Sicht des Apostels Paulus": Gregorianum 42 (1961) 643-700.

10 Para toda esta cuestión de los carismas en la Iglesia, cfr. K. RAHñer, "Lo dinámico en la Iglesia": (Quaestiones Disputatae 5), Herder, Barcelona, 1963, 46-92; A. Turrado, "Lo dinámico en la Iglesia" (K. Rahner): Revista Agustiniana de Espiritualidad 5 (1964) 83-96; ver 85-90; V. CodINA, S. J., Teología de la vida religiosa, Madrid 1968, 173-180. 
autoridad, magisterio y dispensación de los misterios Dios (palabra y sacramentos): apóstoles, presidentes, pastores y doctores, gobernaciones ${ }^{11}$. Este y otros carismas son manifestaciones del Espíritu para utilidad y edificación del Cuerpo de Cristo ${ }^{12}$. El carisma del ministerio o diaconía es conferido visiblemente por la imposición de manos de los apóstoles ${ }^{13}$, y de los presbíteros ${ }^{14}$; y los que lo reciben son llamados dispensadores de los misterios de Dios ${ }^{15}$. San Pedro los llamará también dispensadores de la gracia de Dios ${ }^{16}$.

Evidentemente, estos ministros de Dios deberán unir en sí mismos cl carisma del ministerio y los carismas personales que los hagan fidedignos a los ojos del mundo. Es ésta una exigencia demasiado grave para los que administran los bienes del Cuerpo de Cristo, y sería un subterfugio gravísimo el tratar de camuflar la moral en aras del puro juridismo. Sin embargo, según nota muy bien $\mathrm{K}$. Rahner, se debe evitar el peligro de exagerar las deficiencias de las personas que encarnan el ministerio, porque "el cargo jerárquico mismo, y no sólo su titular efectivo, va marcado de lo carismático, si es que la Iglesia en cuanto constituída jerárquicamente ha de ser hasta el fin de los tiempos la Iglesia del Espíritu permanente, que en virtud de la gracia de Dios y sólo por ella, es incapaz de abandonar en su totalidad la gracia de Dios, su verdad y su santidad, convirtiendo la representación visible de esta gracia, que es la Iglesia, en una sinagoga despojada del Espíritu" ${ }^{17}$.

Los carismas no institucionales. - San Pablo distingue muy bien entre el carisma institucional del ministerio y los carismas no institucionales que el Espíritu distribuye según su voluntad a los miembros del Cuerpo de Cristo para utilidad y edificación de la comunidad ${ }^{18}$. Dice expresamente: "Hay diversidad de dones, pero uno mismo es el Espíritu. Hay diversidad de ministerios, pero uno mismo es el Señor. Hay diversidad de operaciones, pero uno mismo es Dios, que obra todas las cosas en todos. Y a cada uno se le otorga la manifestación del Espíritu

\footnotetext{
11 I Cor. 12, 4-31; Rom. 12, 8; Tesal. 5, 12; Efes. 4, 11.

$12 I$ Cor. 12 y 14, passim.

13 II Tim. 1, 6; Act. 6, 6.

14 I Tim. 4, 14.

15 I Cor. 4, 1; II Cor. 6, 4; Tit. 1, 7.

16 I Petr. 4,10

17 O. c., 52; cfr. H. KüNG, Estructuras de la Iglesia, Estela, Barcelona 1965, 411, sobre la representación fidedigna de la Iglesia en el Concilio Ecuménico. 18 I Cor. 12-14.
} 
para común utilidad. A uno le es dada por el Espíritu la palabra de Sabiduría; a otro, la palabra de ciencia, según el mismo Espíritu; a otro, fe en el mismo Espíritu; a otro, don de curaciones en el mismo Espíritu; a otro, operaciones de milagros; a otro, profecía; a otro, discreción de espíritus; a otro, género de lenguas; a otro, interpretación de lenguas. Todas estas cosas las obra el único y mismo Espíritu, que distribuye a cada uno según quiere" ${ }^{19}$.

Pero sin la caridad o agapé, ni todos estos carismas, ni la pobreza más absoluta, ni la muerte por el fuego servirían de nada para la salvación propia ${ }^{20}$.

Además del aspecto extraordinario que debe revestir siempre lo carismático en la totalidad de la Iglesia, "no se puede negar que existe también la extraordinaria y heroica fidelidad en lo de cada día, el milagro de la serenidad y ecuanimidad, en la que lo maravilloso se realiza calladamente como la cosa más natural" ${ }^{21}$. Esto está en plena consonancia con la doctrina de la Iglesia sobre la necesidad de la gracia para la observancia perseverante de la ley natural y para realizar actos sobrenaturales. Rahner se lamentaba, y con razón, de que no se hablase de los carismas en los tratados sobre la Iglesia, siendo así que lo carismático forma también parte de la esencia de la Iglesia y de hecho siempre han existido en ella. Así lo demuestra la historia de la Iglesia, en especial la historia de todos los días, esa historia oculta y callada más que la grande y oficial, y que no es el menor de los milagros continuamente renovados ${ }^{22}$. Felizmente, el Vaticano II ha subsanado con creces esta laguna en su Constitución dogmática sobre la Iglesia Lumen gentium al hablar de los carismas ordinarios y extraordinarios otorgados por el Espíritu Santo al pueblo cristiano para común utilidad (n. I2), y al introducir en ella a la vida religiosa como un elemento esencial del Cuerpo de Cristo (cap. VI, n. 43-47).

En esta distribución de los carismas, junto con el sacerdocio común de todos los bautizados, se basa fundamentalmente la "teología del laicado", su deber del apostolado y las obligaciones de la jerarquía a este respecto ${ }^{23}$. Es lo que con tanta viveza recomendaba el Apóstol:

\footnotetext{
19) I Cor. 12, 4-11; 12, 27-31.

20 I Cor. 13, 1-13.

21 K. RAHNER, o. c., 59.

22 O. c., 60-63.

23 Cfr. Constitución dogmática sobre la Iglesia, n. 30-38; Decreto sobre el apostolado de los seglares, n. 2-3.
} 
"No apaguéis al Espíritu. No despreciéis las profecías. Probadlo todo y quedaos con lo bueno. Absteneos hasta de las apariencias del mal" ${ }_{24}$

2. La voCACIón RELIGIOSA COMO CARISMa PERSONAL Y ECLESIAL INSTITUÍDO POR CRISTO.

Además de la oposición inicial de muchos Padres Conciliares para introducir el cap. VI "De los religiosos" en la Constitución dogmática Lumen gentium ${ }^{25}$, aún sigue muy arraigada en muchos teólogos la mentalidad de que la vida religiosa o profesión de los consejos evangélicos no puede ostentar un origen divino, es decir, que no fue instituída por Cristo. Es ésta una cuestión fundamental, que condiciona en gran parte el verdadero sentido de la vida religiosa en la Iglesia.

Es cierto que no consta históricamente el origen de la expresión consejos evangélicos, reservada para designar a la tríada: pobreza, castidad y obediencia. Si nos limitamos al Evangelio, no dudamos en afirmar con E. Ranwez que todas las invitaciones, explícitas o implícitas, a seguir los ejemplos de Jesús pueden considerarse como otros tantos consejos evangélicos; y que la idea de consejo en el sentido riguroso de la palabra sólo se encuentra claramente expresada en el Evangelio con respecto a la virginidad y a la pobreza: cuando Jesús declara que la castración voluntaria por el reino de los cielos (propter regnum caelorum) está reservada únicamente a aquellos que "lo pueden comprender", es decir, a los que han recibido ese don de Dios ${ }^{26}$; y cuando sugiere al joven rico el abandono total de sus bienes con vistas a su función personal en la economía de salvación ${ }^{27}$. "Según esto, dice Ranwez, no habría más que dos consejos evangélicos" ${ }^{28}$. El mismo autor afirma que "mantener en la mente o en el lenguaje una necesaria y exclusiva relación entre la idea de consejo evangélico y la de una conducta reservada a la profesión religiosa sería sencillamente engañarse" ${ }^{29}$. Más adelante matiza estas afirmaciones, tomando a Jesucristo

24 I Tesal. 5, 19-22.

25 Cfr. M. Llamera, O. P., Cap. VI, "De los Religiosos". Introducción: Concilio Vaticano II. Comentamios a la Constitución sobre la Iglesia, BAC, Madrid 1966, 798-800.

26 Mt. 19, 12.

27 Mt. 19, 21; Mc. 10, 21; Lc. 18, 22. ver 76 .

E. RANWEz, ¿Tres consejos evangélicos?: Concilium, 9, nov. 1965, 78-81;

29. Ibid., 77 . 
como modelo vivo de la vida religiosa. Sin embargo, teológicamente hablando, la relación de la vida religiosa con la doctrina evangélica y con el ejemplo de Cristo es mucho más íntima y profunda de lo que algunos autores parecen suponer ${ }^{30}$.

ANALOgÍa CON LA INSTitución DIVINA DE LOS SACRAMENTOS.-Suárez tiene a este respecto un pasaje en el que compara la institución de la vida religiosa con la institución divina de los sacramentos, que nos servirá de grande utilidad para plantear teológicamente toda la cuestión. "Digo, pues, en primer lugar: el estado religioso fue dado e instituído inmediatamente por Cristo Nueistro Señor "en sí y en cuanto a su sustancia" (secundum se et quoad substantiam suam) y, por lo tanto, puede decirse que es de derecho divino, no obligatorio sino de consejo. Esta es la opinión de todos los católicos. Digo en segundo lugar: Que Cristo Señor instituyó el estado religioso en cuanto a todos los elementos que pertenecen a la sustancia de tal estado, aunque no instituyera determinación alguna particular para esta o aquella regla y circunstancias. Pero eso basta para poder afirmar que él instituyó tal estado. Esta última parte es de por sí evidente; porque una cosa se llama propiamente tal por razón de su sustancia y esencia y, por lo mismo, el que produce la sustancia de esa cosa, la produce absolutamente, aunque no le dé lo accidental. Del mismo modo se dice que Cristo instituyó los sacramentos, porque enseñó todos los elementos que son de su sustancia, aunque dejara a la Iglesia lo accidental" ${ }^{31}$.

Esa breve referencia de Suárez a la institución divina de los sacramentos nos da la pauta para adentrarnos en la búsqueda de una respuesta teológica satisfactoria a esta cuestión fundamental de la "teología de la vida religiosa". Se trata de una analogía, pero que hoy reviste una importancia muy especial, si tenemos en cuenta la complejidad de los estudios histórico-teológicos en torno al origen divino de los sacramentos. La analogía resulta así mucho más perfecta y más rica de consecuencias de lo que en otros tiempos pudieron sospechar.

30 B. Schwank, "Kann das Ordensleben biblisch begründet werden": Erbe und Auftrag 44 (1968) 409-413; V. CodinA, S. J., Teología de la vida religiosa, Madrid 1968, 45 ss.

31 SuÁREz, De Statu religioso, tr. 7, lib. 3, c. 2 ; cfr. S. Theol., 2-2, q. 88, a. 4, ad 3; Th. SCHAEFFER. De Religiosis, Romae 1947, n. 44, 17; TABERAAntoÑana-E scudero, C. M. F., Derecho de los Religiosos, 4 ed., Madrid 1962, n. 4; A. Royo MaRín, O. P., La vida religiosa, Madrid 1965, n. 4, 5; otros textos en M. Liebana, "Vocacionesi para ambos cleros": Actas del II Congreso Nacional de Religiosos, Madrid 1961, t. II, 152 ss. 
El Evangelio nos habla solamente de la institución divina, expresa e inmediata, de tres, o tal vez de cuatro sacramentos: bautismo, Eucaristía, penitencia y probablemente el orden. La confirmación aparece durante los primeros siglos como un rito unido a la liturgia bautismal. De la extremaunción se habla expresamente por primera vez en la Epístola de Santiago (5, I4-15). El carácter sacramental del matrimonio cristiano se irá perfilando poco a poco en la liturgia y en la exégesis bíblica de los Santos Padres. Asimismo, el rito sacramental del orden y de sus diversos grados llegará envuelto en un sin fin de discusiones basta que Pío XII zanjó la cuestión en 1947 al fijar definitivamente la materia y la forma del mismo (D. 2301). El número septenario de los sacramentos, base para una teología general sobre los mismos, aparecerá por primera vez en el siglo xir, como consecuencia de la lucha contra Berengario († I088), que había negado la presencia real de Cristo en la Eucaristía.

Y, sin embargo, el Concilio de Trento, haciéndose eco de la doctrina tradicional de Oriente y Occidente, definió solemnemente contra los Reformadores que los siete sacramentos de la Nueva Ley fueron instituídos por Jesucristo Nuestro Señor (D. 844).

Con vistas a robustecer la apologética sacramental en el diálogo con los protestantes, y teniendo en cuenta la falta de textos evangélicos explícitos en torno a la institución por Cristo de los cuatro sacramentos (confirmación, orden, matrimonio y extrema-unción), Karl Rahner afirma que la institución misma de la Iglesia por Cristo como sacramento primordial o protosacramento (Ursakrament) implica ya de por sí la institución por Cristo de toda su estructura sacramental, aunque algunos ritos hayan surgido más tarde ante ciertas situaciones decisivas de la vida de los fieles cristianos: "Un acto fundamental de la Iglesia, que pertenezca realmente a la esencia de la misma en cuanto presencia histórica, escatológica de la salud, dirigido al individuo en sus situaciones decisivas, es ya eo ipso un sacramento, aun cuando sólo más tarde hubiera de surgir la reflexión sobre esta su peculiaridad sacramental promanante del ser de la Iglesia. La institución de un sacramento puede también - lo cual no quiere decir que deba siempre-, ocurrir por el simple hecho de que Cristo fundó la Iglesia con su carácter de protosacramento. Por donde se ve también que el tratado De sacramentis in genere, bien comprendido, no es una formulación abstracta de la esencia de los sacramentos en particular, sino que forma parte del tratado de la 
Iglesia, que precede realmente a la doctrina de los sacramentos en particular, en lugar de seguirlos como una generalización a posteriori, dado que sólo partiendo del tratado del protosacramento se puede reconocer la sacramentalidad de más de un sacramento" ${ }^{32}$.

Muchos teólogos no están de acuerdo con esta teoría de Rahner ${ }^{33}$. Para ellos, la verdadera institución de los sacramentos por Cristo, que define el Tridentino, implica la institución directa de los elementos esenciales de los mismos, es decir, el signo sacramental (materia y forma) y su gracia específica.

La teoría de Rahner, aplicada por analogía a la vida religiosa, nos lieva directamente a la conclusión de que la institución de la Iglesia csencialmente carismática implica ya de por sí la institución divina del don-carisma de la vida religiosa o profesión de los consejos evangélicos. Y así lo afirma expresamente el mismo Rahner: "Una orden religiosa no es una asociación privada de hombres que quieren por cuenta propia encauzar su vida espiritual, sino que es la concreción histórica y social de una vida según los consejos evangélicos, cosa que es esencial a la Iglesia misma. Porque en la Iglesia no puede faltar esa práctica de los consejos y, por cierto, de una manera institucional y social, de forma que esta categoría esencial de la Iglesia se haga así concreta y manifiesta al mundo. En este sentido las Ordenes religiosas son una parte de esa manifestación sensible de la gracia divina, que eleva al hombre sobre sus propias posibilidades humanas hasta la vida misma de Dios que es esencial a la Igilesia" ${ }^{34}$.

Por otra parte, si nos ceñimos a la opinión de la institución directa e inmediata de todos los sacramentos por Cristo, la analogía teológica se nos ofrece rica de contenido.

Cristo expresó con toda claridad la existencia de los carismas de la virginidad por el reino de los cielos ${ }^{35} \mathrm{y}$ de la pobreza para unirse a él y seguirle, a ejemplo de los Apósoles ${ }^{36}$. Además, su obediencia al Padre hasta la muerte y muerte de cruz aparece en todo el Evangelio como el modelo que habrán de imitar todos los que deseen ser verdaderos discípulos de Cristo, y así lo recomienda vivamente el Apóstol a todos los

\footnotetext{
32 K. RAHNER, La Iglesia y los sacramentos, Herder, Barcelona 1964, 44-45.

33 Cfr. W. A. vaN Roo, S. J., "Reflections on Karl Rahner's "Kirche und Sakrament": Gregorianum 44 (1963) 465-500.

34 Cfr. K. RAHNER: Geist und Leben 33 (1960).

35 Mt. 19, 12.

36 Mt. 19, 21 ss.
} 
cristianos ${ }^{37}$. Asimismo, la vida común surge en la Iglesia como un fruto de la doctrina y de la vida de Cristo: su vida común perfecta con los Apóstoles y con los discípulos que le siguen, su insistencia en la unión fraterna más íntima posible de sus discípulos, y esa cierta concretización del programa evangélico en la primera comunidad de Jerusalén, a cuyo ejemplo irán surgiendo más tarde todas las instituciones de vida religiosa en común.

Ahora bien; si la institución de un signo sensible al que está ligada una gracia específica implica la institución divina de un sacramento, del mismo modo el espiritu de vida común con sus Apóstoles y discípulos, el deseo de la unión fraterna más íntima de sus fieles, los carismas de la virginidad y de la pobreza, y el ejemplo de su obediencia sin límites al Padre: todo esto, ordenado a la perfección y salvación del hombre (por el reino de los cielos), nos induce a afirmar, por su analogía con la institución de los sacramentos, que la vida religiosa o la profesión de los consejos evangélicos en una vida comunitaria es fundamental y sustancialmente de origen divino, por ser un don o carisma que el Señor dio a su Iglesia para siempre.

\section{Origen carismático e instuticional de la vocación y Vida RELI- GIOSAS Y SUS CONSECUENCIAS.}

Las distintas formas de organización de vida religiosa o profesión de los consejos evangélicos son directa e inmediatamente de origen carismático y a la vez eclesiástico. En efecto; el fundador o fundadores de una orden religiosa son hombres carismáticos, movidos por el Espíritu de Cristo, que distribuye los carismas según su voluntad. Asimismo, la autoridad de la Iglesia o el carisma institucional del ministerio aprueba la autenticidad de esois carismas particulares y les confiere así perennidad y apoyo para utilidad y edificación de los individuos y de todo el Cuerpo de Cristo. Así lo dice expresamente el Vaticano II: "Los consejos evangélicos de la castidad consagrada a Dios, de la pobreza y obediencia, fundados en las palabras y ejemplos del Señor y recomendados por los Apóstoles, por los padres, doctores y pastores de la Iglesia, son un don divino que la Iglesia recibió del Señor y que con su gracia se conserva perpetuamente. La autoridad de la Iglesia, bajo la guía del

$37 \quad$ Filip. 2, 1-11. 
Espíritu Santo, se ha preocupado de interpretar esos consejos, de regular su práctica y de establecer también las formas estables para vivirlos. Por eso, cual árbol que se ramifica maravillosa y abundantemente en el campo del Señor en virtud del germen divinamente otorgado (ex germine divinitus dato), así han ido creciendo las diversas formas de vida solitaria y común, y las diversas familias que se desarrollan tanto para el provecho de sus miembros como para el bien de todo el Cuerpo de Cristo" ${ }^{38}$.

Esta autoridad institucionalizadora de la Iglesia con respecto a las diversas formas de profesión de los consejos evangélicos se funda en la teología bíblica del carisma. El Vaticano II dice que esa profesión es un estado, formado por los que gozan de un don particular en la vida de la Iglesia para contribuir a la misión salvífica de la misma ${ }^{39}$; "un estado, constituído por la profesión de los consejos evangélicos, el cual, aunque no pertenezca a la estructura jerárquica de la Iglesia, sin embargo pertenece de un modo indiscutible a su vida y a su santidad" ${ }^{40}$. $\mathrm{Y}$ al referirse a los institutos no clericales, dice: "La vida religiosa laical, tanto de hombres como de mujeres, constituye de por sí un estado completo de profesión de los consejos evangélicos" ${ }^{41}$. Por el hecho mismo de ser un estado eclesial, que presupone un don o carisma especial de Dios, la vida religiosa queda esencialmente ligada a la jerarquía eclesiástica.

San Pablo insiste en que los carismas extraordinarios son en último término para la utilidad y la edificación del Cuerpo de Cristo. Por eso, él mismo da una serie de normas muy precisas para regular el uso de los distintos carismas ${ }^{42}$, a fin de que todo se desarrolle "con decoro y orden" ${ }^{43}$. De hecho, la Iglesia ha ejercido siempre esa autoridad con respecto a la vida religiosa, al principio mediante los obispos y más adelante directamente por los mismos Romanos Pontífices. Baste recordar que ya en el año 385 el Papa S. Siricio, en una carta a Himerio, abispo de Tarragona, le mandaba que confiriera las órdenes sagradas a todos los monjes, cuya santidad de vida e instrucción de las verdades de la fe lo aconsejaran (D. 9o). 'Durante la Edad Media, los Papas aprue-

\footnotetext{
38 Const. dogmática sobre la Iglesia, n. 43; Decreto sobre la adecuada renovación de la vida religiosa, $\mathrm{n}$. 1 .

3.9. Const. dogmática sobre la Iglesia, n. 43.

40 Ibid., n. 44.

41 Decreto sobre la adecuada renovación de la vida religiosa, n. 10.

42 I Cor. 14.

43 Ibid. 14, 40.
} 
ban direcamente todas las reglas y constituciones de las órdenes religiosas, y defienden con denuedo a las órdenes mendicantes o "clerus Papae". En el 1256, Alejandro IV defiende la sublimidad de la vida religiosa contra los ataques de Guillermo del Santo Amor (D. 458-459). Martín V condena las proposiciones durísimas de Wicleff y de Hus contra la vida religiosa, en especial contra las órdenes mendicantes (D. 600-605, 611, 614-615, 624-625; 651, 680); y León X reprueba las incipientes exageraciones de Lutero (D. 78I). Algunas observaciones, sobre todo por parte de los Reformadores, ponen al vivo los abusos y deficiencias de muchos religiosos de su época; sin embargo, su error fundamental a este respecto consistió precisamente en negar el carácter carismático institucional de la Iglesia y su autoridad para regular la práctica de los consejos evangélicos, llegando así a negar la existencia de la vida religiosa como un estado dentro de la misma Iglesia. De esto a la anarquía y a la supresión radical de la vida religiosa no había más que un paso.

Las consecuencias de toda esta doctrina en torno a la vocación y vida religiosas como carisma, pueden ser reducidas a tres postulados fundamentales, que surgen como conclusiones teológicas.

I. La autoridad de institución de la jerarquía con respecto a la profosión de los consejos evangélicos implica ya de por sí la actitud de todas las formas de vida religiosa a ser reguladas, cambiadas y hasta suprimidas por dicha jerarquía eclesiástica. La misma fidelidad total a la Iglesia de todos los fundadores lleva en sí implícita esa misma actitud sin limitaciones.

La verdadera limitación a este respecto se la impone a la jerarquía la obligación moral de respetar los carismas de Dios, según lo ordenaba ya San Pablo: "No apaguéis al Espíritu" ${ }^{44}$. Por eso, como nota muy bien K. Rahner, "la necesidad interna con que están ligados en la Iglesia el carisma y el sufrimiento no da carta blanca a las autoridades y demás personas no carismáticas para mostrarse irracionales y obstinadas contra tales mociones carismáticas... Las autoridades eclesiásticas no tienen por tanto derecho a cometer errores con el pretexto de que un espíritu, si realmente procede de Dios, sabrá abrirse camino no obstante su resistencia. Con ello sólo logran añadir sufrimientos a los ya inevi-

44 I Tesal. 5, 19. 
tables, cometiendo una injusticia contra Dios, los carismáticos y la Iglesia" ${ }^{45}$.

2. Autoridad delegada de todos los superiores religiosos. Es muy importante recordar siempre que todos los superiores religiosos tienen solamente una autoridad delegada por el Papa o por los obispos, según que su instituto sea de derecho pontificio o diocesano. Pío XII se lo recordó ya con gran viveza a los superiores generales, ante el surgir de ciertas posturas abusivas ${ }^{46}$. Y el Vaticano II, después de afirmar el carácter eclesial del estado religioso, nos enseña que el Papa es el superior supremo de todas las órdenes religiosas, que todos deben prestar a los obispos la debida reverencia y obediencia según la leyes canónicas y que "es la misma Iglesia, con la autoridad recibida de Dios, la que recibe los votos de los profesos, les obtiene del Señor, con la oración pública, los auxilios y la gracia divina, los encomienda a Dios y les imparte una bendición espiritual, asociando su oblación al sacrificio eucarístico" ${ }^{47}$. Pablo VI insiste de nuevo en esto ${ }^{48}$.

Según esto, los superiores religiosos deberán prestar obediencia total a la jerarquía de la Iglesia, de la cual han recibido la potestad de jurisdicción delegada, y deberán acomodarse plenamente a las características de toda autoridad eclesiástica según la voluntad de Cristo. Así mismo, bajo el punto de vista teológico, la terminología canónica que equipara a los superiores religiosos mayores con los ordinarios de lugar, debería ser matizada teniendo en cuenta la diferencia esencial entre la autoridad propia del Papa y de los obispos residenciales y su autoridad meramente delegada.

3. Actitud personal de sumisión y de fidelidad a la jerarquía eclesiástica. Esta actitud de todos y cada uno de los religiosos promana lógicamente de los postulados anteriores. Por eso, toda rémora tácita - expresa a seguir las directrices de la Iglesia, y de un modo especial las del Vaticano II, es una negación del mismo voto de obediencia.

45 K. RAHNER, Lo dinámico en la Iglesia, 88-90; H. KüNG, "La estructura carismática de la Iglesia": Concilium 4 (1965) 44-65; J. PereA, "Tensiones entre carisma e institución": Iglesia Viva 13 (1968) 27-50; J. L. SANTos, "Jerarquía y carisma": Ius Canonicum 7 (1968) 321-364.

46 "Alocución a los Superiores generales establecidos en Roma" (11 febrero 1968): $A A S 50$ (1958) 153.

47 Const. dogmática sobre la Iglesia, n. 45.

48 Alocución Magno Gaudio: AAS 56 (1964) 570-571. 
El apego testarudo a ciertas costumbres y usos, calificados por el Vaticano II de extemporáneos e ineficaces, está resultando ya a los ojos del mundo como algo inconcebible y absurdo.

\section{RESPONSABILIDAD INDIVIDUAL: DURACION O VOCACION TEMPORAL}

Es éste uno de los problemas más delicados con que se enfrenta actualmente la "teología de la vida religiosa". ¿Puede darse una verdadera vocación religiosa y, al mismo tiempo, temporal? Aún más: La profesión de votos solemnes o perpetuos "hasta la muerte" (usque ad mortem), que implica la entrega total y perenne del individuo a Dios y la aceptación divina de esa entrega por medio de la Iglesia, ¿puede ser sincera y eficaz durante un cierto período de tiempo, dejando de serlo después por un abandono legítimo y hasta necesario de la vida religiosa?

Antes de adentrarnos en este delicado problema, quisiéramos hacer algunas observaciones previas. En primer lugar, la constatación común de que la vida religiosa o la profesión de los consejos evangélicos es un lugar teológico, es decir, una fuente de conocimiento de la teología (como lo puede ser la liturgia), ha de ser llevada hasta sus últimas consecuencias. Si es un lugar teológico por ser un estado eclesial, un hecho perenne en la vida de la Iglesia, lo es con todos los elementos y características que reviste su institucionalización y la praxis. Ahora bien; la praxis de la Iglesia, especialmente en estos últimos años, de dispendar los votos solemnes y perpetuos por alguna causa justa, entra a formar parte de ese lugar teológico y reclama una explicación teológica adecuada, que desdramatice esa situación casi siempre penosa para los religiosos que tienen que vivirla. Naturalmente, en esta explicación va también incluído el celibato, al que muchos religiosos están también obligados en virtud de las órdenes sagradas y cuya dispensa se va haciendo cada vez más frecuente. En segundo lugar, quisiéramos advertir que no se trata aquí de criticar la vida y la doctrina de la Iglesia, sino de analizar teológicamente esa vida y esa doctrina. Todos los fenómenos de su larga historia presentan muchos misterios inexplicables si no se los sitúa en el medio ambiente de cada época. ¿Quién podría comprender hoy, por ejemplo, la legitimidad de la Inquisición? El carácter 
también esencialmente humano de la Iglesia está expuesto a estos riesgos y humillaciones, que hemos de aceptar como una cruz y una humillación a ejemplo del Cristo anonadado (kénosis) y despreciado.

Bajo esta perspectiva, veamos si hay una explicación teológica para el problema que nos ocupa, y que se va abriendo camino paulatina y temerosamente en algunas publicaciones modernas.

I. El peligro del excesivo "Juridismo" y de lo apersonal.

Frente al "humanismo renacentista", y al "individualismo" de la Reforma que, con su sacerdocio común de todos los fieles, negaba de raíz el sacramento del orden y la jerarquía eclesiástica de origen divino, la eclesiología católica postridentina se proyectó casi exclusivamente hacia la defensa de las estructuras jerárquicas de la Iglesia de Cristo, cayendo así en un juridismo muy pronunciado y muy apersonal. Esta postura, que prácticamente se ha conservado hasta hace muy pocos años (la Encíclica Mystici Corporis de P'́o XII, año 1943, significó un cambio de ruta definitivo) influyó notablemente en la legislación canónica y, por ende, en la organización y en la vida de las órdenes religiosas. Aun durante la última reforma del Código de Derecho Canónico, promulgada por Benedicto XV, los defensores del "personalismo", entre los que se hallaba el futuro Pío XII, tuvieron que resignarse ante el triunfo del "juridismo". Las consecuencias de toda esa corriente jurídica y bastante apersonal han sido ya demasiado lamentables como para que podamos permitirnos el lujo de seguir separando lo institucional de lo carismático, lo jurídico de lo moral, lo social de lo personal. Precisamente, esto es lo que ha tratado de subsanar el Vaticano II con su doctrina sobre la Iglesia, Misterio, Pueblo de Dios y Cuerpo Místico de Cristo, vitalizado por el Espíritu y por sus carismas de todo género, y con su insistencia en los derechos fundamentales de la persona humana, en la libertad religiosa, en el ecumenismo y, en nuestro caso, en el sentido evangélico, personal, cristológico y eclesial de la vida religiosa. Por eso, amaestrada por una larga experiencia, la Iglesia actual rehuye toda sombra de triunfalismos y de endiosamientos efímeros del hombre, para convertirse de nuevo en lo que tiene que ser, en la Ecclesia Crucis. Todas sus estructuras vuelven a revestirse del sentido evangélico de servicio desinteresado a la humanidad.

Bajo esta perspectiva, la vida religiosa no sólo interesa ya consi- 
derada como un estado eclesial, sino también como una vocación o carisma individual para la santificación y salvación de la persona y el servicio de la Iglesia.

\section{PERSona y COMUNIDAD.}

La teología paulina del Cuerpo de Cristo, con toda su evolución a través de los siglos hasta la Constitución Lumen gentium del Vaticano II, nos enseña que la perfección cristiana y la salvación se realizan en un plano esencialmente personal y social a la vez. La metánoia evangélicd o renovación interior del hombre exige ciertamente una respuesta individual al llamamiento divino de salvación; pero, al mismo tiempo, esa respuesta no puede darse sin una relación íntima, explícita o implícita, con Cristo y con su Iglesia. El hombre se encuentra así sumergido de lleno en una "historia de salvación" que reviste un carácter esencialmente personal y social.

El filón doctrinal de la tradición cristiana que mejor expresa esa doble perspectiva es sin duda la "teología de la imagen trinitaria del hombre", de profunda raigambre bíblica, y que tanto influyé en toda la teología de los Santos Padres y de las órdenes monásticas desde los primeros siglos. J. B. Ladner ${ }^{49}$ ha demostrado que todos los movimientos de reforma de la Iglesia durante los primeros siglos tenían como raíz y substrato a la teología del hombre hecho a imagen de Dios, de esta imagen desfigurada por el pecado y de toda la vida cristiana concebida como un esfuerzo para reformarse a imagen de Jesucristo y del modelo evangélico ${ }^{50}$.

$\mathrm{El}$ aspecto social de esa reforma aparece en la función ineludible de la Iglesia y de sus sacramentos para que pueda llevarse a cabo, y aparece también en la importancia que atribuyen a este respecto a la profesión de los consejos evangélicos. Pero, mientras el monacato oriental, más directamente influenciado por el neoplatonismo, busca ante todo al monje ideal-universal, el ideal monástico de San Agustín, para cuya comprensión se ha de atender a toda su filosofía y teología, es de un carácter mucho más personal y más dinámino al servicio de la Iglesia. Como nota muy bien E. Przywara: "Agustín opone a la anápausis

49 G. G. LADNER, The Idea of Reform. Its Impact on Christian Thought and Action in the Age of the Fathers, Cambridge (USA) 1959, XIII-553.

50 Cfr. Y. M.-J. Congar, Santa Iglesia, Barcelona 1965, 137. 
(reposo, soledad) escatológica y oriental la acción viva de la caridad. Pero en esta caridad ve él, sobre la necesidad del apostolado, el libre ocio del amor, el aliento más puro del eterno Sábado, que se revela en todas las misiones más activas de la Ciudad de Dios. Así pasa a una escatología de la misión específicamente occidental: es el ethos de la humildad, pobreza, santa indiferencia. Por eso, Agustín es el Padre de las escuelas de espiritualidad de las grandes Ordenes Religiosas, desde la Orden de San Benito hasta la Compañía de Jesús. Es la escatología de la Oración sacerdotal: No son del mundo, pero son enviados adentro del mundo" ${ }^{51}$.

Este fuerte personalismo de San Agustín, radicado en toda su antropología sobrenatural, frente al hombre-especie, ideal o universal del helenismo, y que tanto habría de influir en la mentalidad occidental, :s reconocido como un mérito inigualable por los mismos humanistas ateos de nuestros días. Así, el filósofo comunista francés Roger Garaudy escribe: "Los marxistas no olvidan lo que deben al cristianismo, como tampoco a las otras grandes doctrinas o ideales de vida del pasado, que aportaron algo nuevo a la forma humana. Al reinvindicar con orgullo là herencia del humanismo y del racionalismo griegos, los marxistas saben que el cristianismo creó una dimensión nueva del hombre: la de la persona humana. Esta noción le era tan extraña al racionalismo clásico, que los Padres no podían encontrar en la filosofía griega las categorías ni las palabras para expresar la nueva realidad. El pensamiento no concebía que lo infinito y lo universal pudieran expresarse en una persona. Sólo en el siglo iv logró superarse esta contradicción, porque entre los Padres griegos subsistía cierto platonismo, y había de ser sólo San Agustín quien expresaría la dimensión de la subjetividad y su valor" ${ }^{52}$. El equilibrio entre la persona y la sociedad y entre el religioso y la comunidad será desde San Agustín, al menos en principio, una de İas notas características de todas las Ordenes religiosas del Occidente. $\mathrm{Y}$ decimos al menos como principio, porque una cierta pérdida de ese personalismo equilibrado, que implica de por sí el amor de Dios y del prójimo, ha sido un duro golpe para la teología y la legislación de la Iglesia Católica, y de ello nos acusan con insistencia nuestros hermanos

51 E. Przywara, Augustinus. Die Gestalt als Gefüge, Leipzig 1934, 19-20; cfr. L. Cilleruelo, O. S. A., El monacato de San Agustín, Valladolid 1966, 30.

52 R. Garaudy, ¿Qué es la moral marxista?, Buenos Aires 1964, 59-60; ID., Marxisme du $20^{\ominus}$ siècle, Paris-Genève 1966, 142. 
de la Reforma, que se profesan con orgullo "fieles seguidores de San Agustín".

Antes de analizar este fenómeno histórico-teológico, creemos conveniente recordar aquí que la vida religiosa es solamente un medio para alcanzar la perfección cristiana, que consiste esencialmente en la caridad. El Vaticano II, después de proponer a Jesucristo como único modelo de perfección, y de enseñarnos una vez más que la santidad cristiana es única para todos ${ }^{53}$, comienza su exposición de los consejos evangélicos afirmando que la caridad es la esencia de la perfección cristiana y la que informa a todos los demás medios de santificación y los conduce a su fin ${ }^{54}$. Por eso, la continencia es "un signo y un estímulo de la caridad", y la pobreza y la obediencia "un testimonio e imitación de la caridad y humildad de Cristo" ${ }^{55}$. Los consejos evangélicos deben servir "para progresar en la vida de caridad con espíritu gozoso" ${ }^{56}$ y para librar al fiel cristiano "de los impedimentos que podrían apartarle del fervor de la caridad y de la perfección del culto divino" ${ }^{57}$. Ya San Agustín no dudaba en afirmar que los verdaderos monjes son únicamente aquellos en cuyo corazón arde la caridad perfecta de Cristo: "Non ergo habitant in unum, nisi in quibus perfecta fuerit caritas Christi" ${ }^{58}$.

Teniendo en cuenta ese personalismo bien entendido de toda la economía cristiana y que la vida religiosa no es más que un medio para alcanzar la perfección común de la caridad, no nos resultará ya difícil poder comprender sin temores ni perplejidades la posible temporalidad de la vocación religiosa de algunos verdaderamente llamados.

\section{La teología de LA GRACia y LA vocación RELIGIOSA.}

Siendo la vocación religiosa un carisma o don de Dios, es evidente que entra a formar parte del tratado sobre la gracia, con las características de una gracia accidental en orden a la perfección cristiana.

Según esto, creemos que la clave para explicar la posible temporaiidad de la vocación religiosa, reconocida en la praxis de la Iglesia como

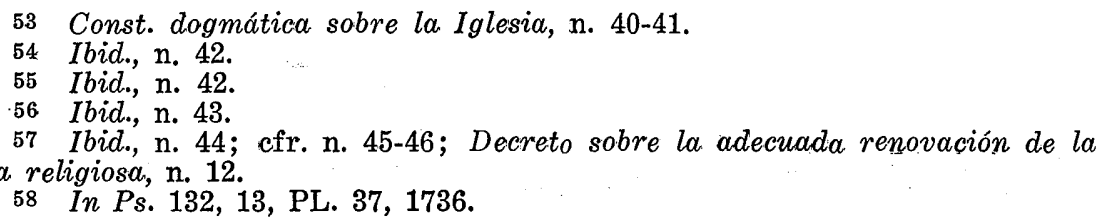


un hecho relativamente frecuente, está en estos axiomas clásicos del tratado sobre la gracia, rectamente entendidos: La gracia presupone a ia naturaleza (Gratia praesupponit naturam); y La gracia no destruye, sino que perfecciona a la naturaleza (Gratia non destruit, sed perficit naturam). La pena es que, ya desde la Edad Media, la interpretación tcológica de estos axiomas ha corrido la misma suerte que la eclesiología y la legislación canónica. El influjo de la filosofía aristotélica, de tipo esencialista, hizo que la teología aristotélico-tomista se redujera a concebir esa naturaleza, presupuesta por la gracia, como algo metafísico, es decir, como la esencia humana considerada en cuanto principio de operaciones y, por lo tanto, como algo apersonal. Es, pues, una naturalezaespecie, abstracta y "especulativizada". En cambio, para el agustinismo, fiel al espíritu de su Maestro, lo que cuenta es la persona concreta y no el hombre-especie. Esa naturaleza, presupuesta por la gracia, es una naturaleza concreta, personal, propia de cada hombre con todas sus virtualidades, anhelos y limitaciones.

Esta diferencia puede observarse ya en cuanto a la noción de la gracia en los comentadores medievales de San Pablo. Los agustinianos consideran la gracia como algo dinámico, según las categorías de la acción y del movimiento, como un elemento psicológico y como una actitud moral; mientras que los aristotélicos se ciñen a su aspecto ontológico, y la consideran como un hábito o como una segunda naturaleza en el orden sobrenatural ${ }^{59}$.

Estas diferencias se prolongaron a través de los siglos, pero sin afectar a la médula del dogma cristiano. En cambio, Lutero y los Reformadores, llevados por su antiescolasticismo radical, dieron carácter de exclusividad a la concepción histórico-psicológica de la naturaleza y al aspecto moral de la gracia (puramente extrínseca), y así contribuyeron indirectamente a que la teología católica se ciñera más y más al aspecto ontológico de la naturaleza y de la gracia. $\mathrm{Y}$ es una verdadera pena que la teoría de la "duplex iustitia" (la gracia habitual y la confianza en los méritos de Cristo), propuesta por el gran Jerónimo Seripando, no fuera aceptada en el decreto sobre la justificación del Concilio de Trento. Con ello se hubieran salvado muchas confusiones y contrastes con los Reformadores.

59) Cfr. Z. Alszeghy, S. J., Nova Creatura. La nozione della grazia nei commentatori medievali di S. Paolo (Analecta Gregoriana, Vol. LXXXI), Romae 1956, IV-284; ver 259 ss.; B. STOECKLE, Gratia supponit naturam. Geschichte und Analyse eines theologischen Axioms, unter besonderer Berücksichtigung seines patristischen Ursprungs, seiner Formulierung in der Hochscholastik und 
Porque el triunfo del aristotelismo-tomista iba a influir definitivamente tn la especulativización de la teología y de la legislación católicas y, por ende, también en la legislación de la vida religiosa ${ }^{60}$.

Los más grandes teólogos modernos, - preferimos no citar nombres-, sin duda debido al contacto con la teología protestante y al influjo de la filosofía existencialista, han contribuído a que el Concilio Vaticano II y con él la teología católica vuelvan a poner en su justo relieve el personalismo fundamental de la economía de salvación y su permanencia ineludible en la sociedad eclesial o Cuerpo Místico de Cristo.

Todo esto nos lleva a la conclusión de que esa naturaleza, presupuesta por la gracia y, por lo tanto, presupuesta también por la vocación religiosa, es la naturaleza concreta de cada persona, tan misteriosa como la vida del hombre, sujeta a un sin fin de evoluciones psico-fisiológicas que muy fácilmente pueden llegar a ser incompatibles con las decisiones perentorias, en nuestro caso con los votos solemnes y perpetuos, tomadas en un momento dado de la existencia. De este modo, se comprende mejor que la temporalidad, aunque con diversos matices, sea un elemento esencial al dinamismo de la naturaleza humana y, por lo mismo, esencial también al dinamismo de la gracia.

Todos los carismas, tanto la gracia habitual y las gracias actuales como los carismas extraordinarios, ordenados a la perfección propia y del prójimo, tienden de por sí a la perennidad, como es perenne la voluntad salvífica universal del Dios que los otorga. Sin embargo, la temporalidad va incrustada en ellos como un injerto nato, porque la persona que los recibe está expuesta a un sin fin de vaivenes, a veces irremediables. La misma gracia habitual comienza en el tiempo, y puede perderse y recuperarse infinitas veces a lo largo de la vida. La misma estructura sacramental de la Iglesia presupone ya esta contingencia. Pero cuando el carisma es simplemente un medio para la perección cristiana, como lo es la vocación religiosa o la profesión de los consejos evangélicos, es fácil prever que en ciertos casos puede llegar a convertirse en un verdadero obstáculo para alcanzar esa perfección e incluso la salvación eterna. Entonces no sólo se puede, sino que se debe abandonar la vida

zentralen Position in der Theologie des: 19. Jahrhunderts (Studia Anselmiana 49), Roma 1962, XXIV-407.

60 Cfr. A. Turrado, "Fe en Cristo y fe en la unidad de los cristianos": Rev. Agust. de Espiritualidad 9 (1968) 5-16. 
religiosa para salvar la vida cristiana, que es lo esencial en la historia de salvación.

Este abandono no indica, pues, necesariamente la falta anterior de la vocación religiosa, que pudo ser incluso extraordinaria. La experiencia cotidiana nos lo confirma con creces y la praxis de la Iglesia se limita a tomar una decisión en conformidad con la situación del religioso durante un cierto período de tiempo, no durante toda la vida. Por eso, no creemos muy caritativo el sentido peyorativo que se da con mucha frecuencia a la célebre frase: ¡Caen los cedros del Líbano!, aplicada a ciertos religiosos notables que han abandonado la vida del claustro.

\section{Condicionamientos de la vocación religiosa.}

A continuación enumeramos algunas de las causas que pueden condicionar la duración de la vocacción religiosa. Después de los postulados teológigos anteriores, bastará un simple enunciado de las mismas para comprender su verdadero alcance.

a) La posible ignorancia real de la materia de los votos. No basta un conocimiento meramente especulativo. Precisamente todos los conatos actuales de renovación de los seminarios y casas de formación tienden a promover la madurez de los candidatos para que sean conscientes de las obligaciones que implica la profesión de los consejos evangélicos. La vida real demuestra a bastantes religiosos, por ejemplo, que su conocimiento del voto de castidad era muy precario e ilusorio; y el voto de obediencia se convierte para algunos en una fuente continua de angustia e inseguridad. De aquí a una neurastenia aguda, que inutiliza al religioso para toda actividad equilibrada y eficaz, no hay más que un paso. Por eso, no es de extrañar que las congregaciones religiosas modernas y los institutos seculares hayan suprimido los votos solemnes, y que en la misma Sagrada Congregación de Religiosos haya hoy día una fuerte tendencia en este mismo sentido.

Algunos autores modernos siguen aplicando a la vida religiosa la perennidad de la fidelidad bíblica, con un gran número indiscriminado de textos ${ }^{61}$. Lo cierto es que no se pueden comparar la opción o fidelidad fundamental a Dios y al cristianismo y las infidelidades conscientes

61 P.-R. RÉGaMy, O. P., "L'aspect définitif de l'engagement religiєux. Sa signification théologique": La vocation, éveil et formation. Problèmes de vie religieuse, Les Editons du Cerf, Paris 1965, 247-264. 
y sin motivo justo a lo prometido (como en el caso de Ananías y Safira), con ciertas promesas humanas, hechas con toda sinceridad en un momento dado, pero siempre condicionadas por un sin fin de circunstancias imprevistas, como puede ser la profesión de los consejos evangélicos.

Los religiosos que se encuentran en esta situación sufren generalmente graves crisis de conciencia. $\mathrm{Y}$, si no encuentran a una persona competente y caritativa a quien recurrir, pueden llegar a la desesperación y a la pérdida de la fe. De aquí la necesidad urgente de buenos directores espirituales y confesores, y de una jerarquía que sepa actuar con espíritu paternal y comprensivo. Está en juego la salvación de muchos religiosos que, bien comprendidos, pueden ser en el mundo excelentes cristianos y apóstoles.

b) La posible evolución psico-fisiológica imprevista, que no depende por tanto de la voluntad del individuo, puede también aconsejar el abandono de la vida religiosa. Esto puede surgir, entre otras causas, por ciertas taras hereditarias que aparecen con violencia cuando menos se piensa; o por disfunciones orgánicas, o por otros accidentes inesperados. Todo esto puede hacer imposible y hasta perjudicial la permanencia en la vida religiosa. Los consultorios psiquiátricos están ya bastante acostumbrados a esta clase de problemas.

c) La llamada psicología del grupo con sus múltiples interacciones La vida de comunidad puede, por diversas razones, llegar a ser ineticaz y hasta perjudicial para un religioso, o para varios, o para todos los que la integran. Aquí cabría un amplio margen para hablar, por ejemplo, de la llamada política de los capitulos, que tanto daño ha hecho y sigue haciendo a las corporaciones religiosas y a los individuos. A veces adquiere tales proporciones que prácticamente desvirtúa el espíritu evangélico de la vida religiosa, con grave escándalo sobre todo de los religiosos más jóvenes. La fuerte oposición de ciertos grupos a la democratızación establecida por el Vaticano II, tratando de seguir refugiándose en un pretendido endiosamiento de las jerarquías de su agrado, es un buen indicio de que las aguas de la vida religiosa no corrían por cauces muy limpios.

Los peligros del excesivo angelismo salen a flote en todas estas situaciones. Se ha querido deshumanizar al religioso en aras de una pretendida sublimación, que no puede darse en la realidad. Porque ningún hombre, sea o no religioso, podrá nunca dejar de ser hombre, con todos sus anhelos y limitaciones; ni nunca podrá renunciar a sus 
derechos fundamentales de persona humana que, por otra parte, le son oficialmente salvaguardados por la Regla y las Constituciones que ha profesado; y no se puede arrinconar impunemente a ningún religioso en virtud de un providencialismo abusivo, al cual solamente se recurre cuando las propias conveniencias lo aconsejan. Este angelismo antihumano y antievangélico ha causado ya demasiados daños, como para que podamos permitirnos el lujo de seguir tergiversando las nuevas d.rectrices de la Iglesia.

d) Además, los designios de Dios sobre una persona pueden manifestarse de muy diversos modos, puesto que él es al mismo tiempo autor de la naturaleza y de la gracia. Varios años de vida religiosa pueden servir, según los designios de Dios, para formar excelentes padres de familia y excelentes apóstoles en el mundo. Por eso, el abandono de la vida religiosa no puede ser catalogado sin más como "una pérdida de la vocación", que muy bien pudo ser verdadera, pero temporal. La praxis actual de la Iglesia con respecto a los que abandonan la vida religiosa o el sacerdocio nos confirma el triunfo del personalismo cristiano, en todo su equilibrio, sobre el juridismo universal y apersonal.
A. Turrado, O. S. A. 